\title{
Utilization of Municipal Solid Waste and Agricultural Waste for Energy Sources: Perspective toward CO-RDF Project in the Western of Thailand
}

\author{
Kittinun Boonrod ${ }^{1}$, Jumpol Kullavanijaya ${ }^{2}$, Viroj Lengrugsa ${ }^{3}$ and Wichid Pumchan \\ ${ }^{1 *}$ Faculty of Humanities and Social Science, Phetchaburi Rajabhat University, Phetchaburi, Thailand \\ ${ }^{2}$ Materials Planning Division, Provincial Electricity Authority, Bangkok, Thailand \\ ${ }^{3}$ Bureau of the Vector Borne Diseases Control, Ministry of Public Health, Nonthaburi, Thailand \\ ${ }^{4}$ Provincial Public Health Office, Ministry of Public Health, Ubonratchathani, Thailand
}

\begin{abstract}
The main objective of the present study was to conduct a public opinion survey on solid fuel development from pineapple and coconut residue and its co-production with municipal solid waste project or the "CO-RDF" Project. Primarily, the aim was to provide a new form of capable and environmentally-friendly source of alternative energy in addition to driving toward actual future applications. The study was based on a survey research design that relied on the Cochran Method to specify the sample population size with a confidence level of 95 percent. Additionally, the survey areas were visited by using questionnaires in a sample composed of 400 cases in Phetchaburi and Prachuab Khiri Khan Provinces, which are the main cultivation areas for pineapples and coconuts in the western region of Thailand.

The significant findings of the study are as follows: The sample group's acceptance of the CO-RDF Project to be implemented in the future equaled a mean score of 3.90 (High Level). The factors found to be correlated with the project's acceptance included awareness of the environmental and energy crises, awareness of social and community development and opportunities and participation, all of which had congruent correlations with the project's acceptance. At the same time, the factors of concern about the environment, concern about health and obstacles in gathering biomass materials were also found to be correlated with project acceptance albeit inversely. Furthermore, the factors correlated with the economic incentives did not significantly affect the level of the project's acceptance. The findings of the present study provide an essential database for related people in driving the project toward effective implementation with cooperation between the people and farmers in reducing the currently widespread problem of the NIMBY syndrome.
\end{abstract}

Keywords: Social Acceptance, Refuse derived Fuel, Biomass, Renewable Energy,

\section{Introduction}

At the present, Thailand through the Department of Alternative Energy Development under the Ministry of Energy, has issued policies to support the project with focus on creating innovations to create various forms of alternative energy. The solid fuel development from pineapple and coconut and its co-production with municipal solid waste project (CO-RDF Project) is one of the projects granted support to respond to the aforementioned policies, whose primary objectives are to create new, capable and environmentally-friendly sources of alternative energy. The project's main objective was to study and develop fuels for combustion and gasification through development in solid fuels consisting of biomass pellet, biomass briquette or refuse-derived fuel (RDF) with municipal solid waste (MSW) and agricultural waste (AGW) providing the main raw materials for co-production in order to most effectively utilize available resources, which was the key concept behind this implementation.

Another policy movement in Thailand is found to be supporting the Waste-to-Energy (WtE) application for decreasing the need to import energy from abroad and help solve the energy crisis in the country. This energy 
scheme is proposed as part of the national Renewable and Alternative Energy Development Plan (AEDP 20152036) for Thailand. According to this plan, the target energy production from renewable energy from MSW in the year 2036 is set at $500 \mathrm{MW}$ where the baseline production in 2014 is at $66 \mathrm{MW}$. In terms of alternative energy production from biomass, the target is much higher at 5,570 MW with the baseline for production in 2014 being 2,452 MW [1]. Therefore, it can be said that Thailand can still significantly enhance its ratio of waste-derived electricity and heat energy production.

Coconut and pineapple are both major crops for Thailand. The Western Region of Thailand is home to particularly large cultivation areas when compared to other regions. In particular, Prachuap Khiri Khan and Phetchaburi are provinces where extensive coconut and pineapple cultivation occurs. According to a report by the Office of Agricultural Economics in 2016, it was revealed that Prachuap Khiri Khan is Thailand's largest cultivation and production area for coconuts. Similarly, both Prachuap Khiri Khan and Phetchaburi account for up to 70 percent of all pineapple production relative to the country's total production [2]. The study was conducted on the large quantities of waste materials resulting from various processes, cultivation activities and product processing of coconuts covering outer coat, middle fibrous coat, shell, upper core leave stalk, frond, bottom core leave stalk and empty fruit bunch and of scraps from pineapple consisting of crown leaves, leaves, sucker, root and stalk. For the most part, these waste materials are discarded inside plantation rows and factory floors, thereby creating waste accumulation and loss of utilization space [3], [4].

At the same time, problems in waste management, particularly municipal solid waste (MSW), indicate a continuously escalating trend caused by population growth, economic growth and changing consumer behaviors, while disposal systems with academically-correct management remain insufficient. According to a survey by the Pollution Control Department in 2016, the amount of municipal solid waste produced within 7,777 local administrative organizations nationwide is over 27.06 million tons, or 74,130 tons per day. Furthermore, waste generation per capita has increased from 1.13 to 1.14 kilograms per person per day. Moreover, as much as 9.96 million tons of old accumulated waste at final disposal sites remain improperly managed [5]. Thus, this crisis is of the utmost importance. In response, the government created a national agenda on waste management and passed a resolution in approval of a roadmap on waste and hazardous waste management in order to urgently resolve problems related to wastes. For the mid-level implementation framework, Phetchaburi and Prachuap Khiri Khan are two of the 26 designated provinces requiring urgent municipal solid waste management for new solid wastes in line with the second stage of the roadmap, which places emphasis on waste reduction, proper sorting of wastes at their sources, center-style solid waste management and disposal using combined technologies with priority on converting wastes into energy, particularly RDF production and increased private investment to achieve maximum effectiveness. [6]

The aforementioned reasons formed the support for the concept to make use of both MSW and AGW in the form of renewable energy and apply the concept in real situations. Thus, studies on fuel types, system effectiveness and project feasibility in the Thai social context and potential social and environmental impacts under the CO-RDF Project required thorough consideration. In the CO-RDF Project's final report [7], a projection of the project's outcomes was able to reflect the potential of RDF solid fuel co-production between MSW and AGW, placing it at approximately 13,000 tons per year with a ratio of AGW at 30 percent. This ratio is effective, appropriate and meets set standards (Fig. 1a-1b). If the findings can be applied as guidelines for improving the management of the aforementioned wastes in the future, a benefit that will be obtained are reduction of municipalities' burdens in waste disposal and reduction in the quantities of agricultural organic wastes produced in the system. Furthermore, other new and old community wastes would be utilized. The target provinces stated above have the MSW management problem as existing capital, particularly at the landfill site of Hua Hin Municipality, Prachuap Khiri Khan, which was one of the sampled locations in the present study. Since the aforementioned locations have been facing waste management problems (Fig. 1c), residents near landfill sites have been protesting and preventing additional waste-dumping by municipal garbage trucks; after over 20 
years, wastes have been piled into a mountain, while other problems such as odors and leachates impact surrounding communities.

However, the general public is more aware of their surrounding environment and therefore, the widely discussed "Not In My Back Yard" (NIMBY) syndrome must be considered when planning for the development of required infrastructures, especial for WtE areas [8]. Similarly, waste management projects in some parts of Thailand is still being opposed by the public and the management team cannot go in to the area. This is mainly because projects in the past failed to create knowledge and awareness of the project with the community members and the general public in the preparation phase. CO-RDF is a new technology and it is still not used in Thailand, however, the project success is highly dependent of the participation from the community members and agriculturists who are the owner of materials. Therefore, the study of the perception of the people is a way to gain important insights that can be applied to support the project and similarly WtE plan. The results of the study will be useful for policy makers in setting up their roadmap and management planning so that they can mobilize the actions to their future targets.
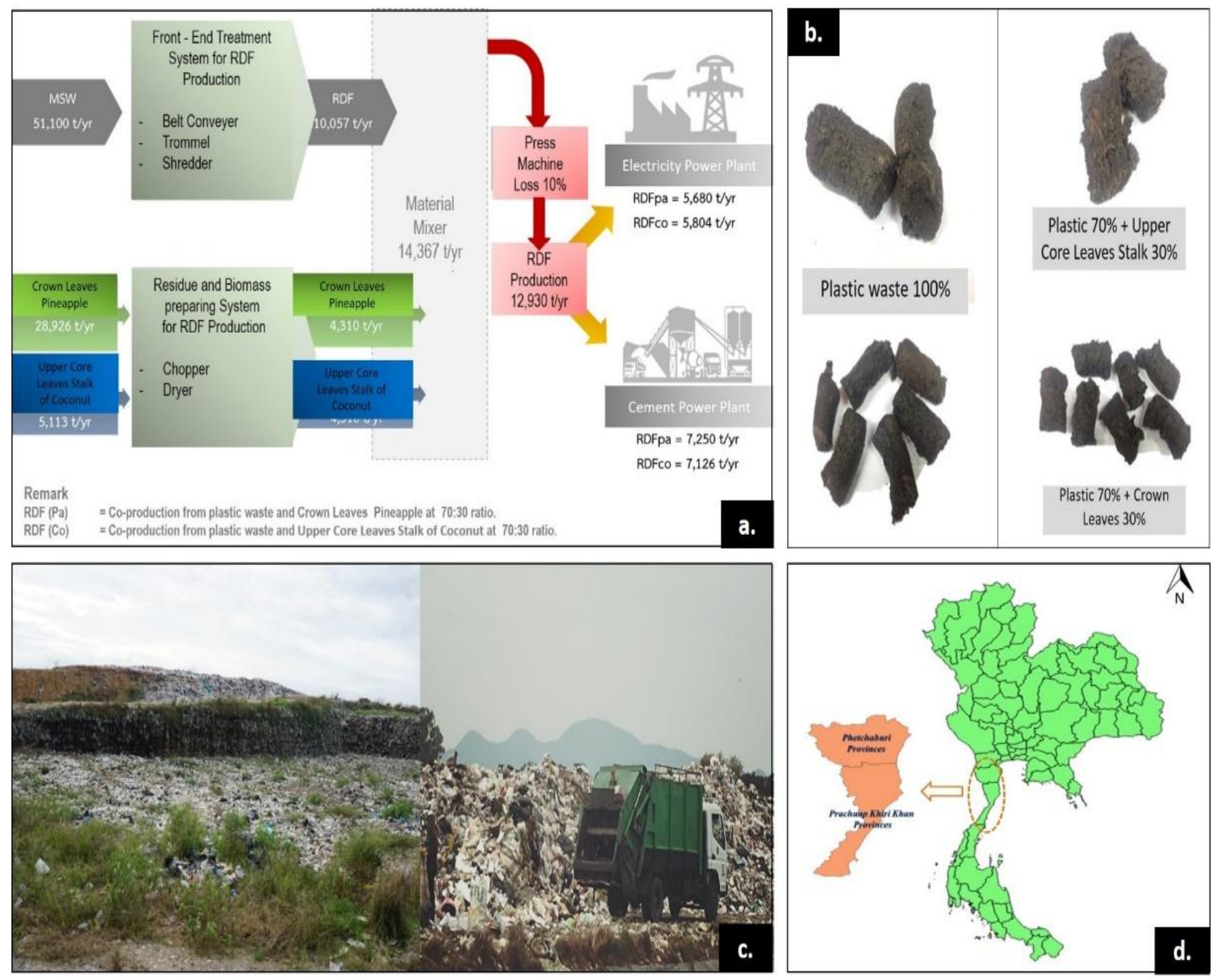

Fig 1: (a) Flow Diagram of CO-RDF Project (b) Example of RDF Production from CO-RDF Project (c) MSW Disposal Site at Hua Hin Municipality (d) Target study area

\section{Methodology}




\subsection{Sample Size}

The present study was conducted within the scope of the CO-RDF Project with two provinces designated as the study areas, namely, Phetchaburi and Prachuap Khiri Khan, both of which represent the largest cultivation areas for pineapple and coconuts in Thailand's western region (fig. 1d). The sample size was set by the Cochran Method [9] by setting the confidence level at 95 percent. The researcher went out into the field to conduct a questionnaire survey with 400 cases covering both provinces and data was collected from January to June 2017

\subsection{Research Tool}

In the present study, the researcher went into the study field to interview farmers there. The instrument used was a questionnaire with open- and close-ended questions. The questionnaire was submitted to the process of examination for accuracy by experts and tested for instrument reliability before conducting the real survey. The reliability analysis by using Cronbach's Alpha Coefficient resulted in a reality score of 0.78 .

The content of study was composed of 4 main topics as follows: 1. Group of attitude on awareness. 2.Group of attitude for project concern 3.Group of incentive and obstacle 4. Social acceptance of CO-RDF Project, distributed to 10 sub-topics and 51 questions, described in fig. 2-5. The scoring system applied is the 5 levels Likert Scale where each of the range are marked as <1.80 being very low, $1.81-2.60$ low, $2.61-3.40$ medium, $3.41-4.20$ high and $4.21-5.00$ very high.

\subsection{Material Survey Method at Peel Yards}

The data obtained was analyzed by using descriptive analysis with the following statistical values: percentage, mean and standard deviation. The data was then analyzed with inferential statistics by using Pearson Product Moment Correlation Coefficient in order to find the correlations between the two variables.

Testing the opinions on various issues led to planning by telling the degree or extent of the correlations by using the $\mathrm{R}$ value. In cases where the $\mathrm{R}$ value approached -1 or 1 , a high degree of correlation was indicated. If, however, the value was near 0 , a low degree of correlation or no correlation at all was indicated. A negative $\mathrm{R}$ value indicated a correlation in the opposite direction, while a positive $\mathrm{R}$ value indicated a correlation in the same direction.

\begin{tabular}{|c|c|}
\hline Issue & Questions \\
\hline $\begin{array}{l}\text { Acceptance of CO-RDF project } \\
\text { (ACCEPT) }\end{array}$ & $\begin{array}{l}\text { - Discussions will be held at the individual, family and community levels in the event that the co-production project of biomass energy from agricultural wastes and } \\
\text { community wastes is implemented in nearby community residential areas (ACPTI). } \\
\text { - Studies can be conducted for additional information in addition to potential benefits and impacts due to the implementation of the co-production project of biomass } \\
\text { energy from agricultural and community wastes in nearby community residential areas (ACPT2). } \\
\text { - Individuals and community members will hold discussions, exchange opinions about or innovate the use of agricultural wastes in various ways and not only for } \\
\text { energy benefits (ACPT3). } \\
\text { - Agricultural wastes will become noticeable both in terms of type and quantity (ACPT4). } \\
\text { - Space can be arranged to experiment with collecting agricultural wastes (ACPT5). } \\
\text { - Implementation of the co-production project of biomass energy from agricultural wastes and community wastes in nearby communities and residential areas will be } \\
\text { a positive undertaking (ACPT6). } \\
\text { - Waste materials from plantations will be gathered once the co-production project of biomass energy from agricultural wastes and community wastes is implemented } \\
\text { (ACPT7). } \\
\text {-There will be no concerns about any potential impact in the event of implementation of the co-production project of biomass energy from agricultural and community } \\
\text { wastes in nearby communities or residential areas (ACPT8). } \\
\text { - People will be glad to participate in activities if events are organized to provide lectures and education or to hear opinions in the event of implementation of the co- } \\
\text { production project of biomass energy from agricultural wastes and community wastes in the vicinity of your community residential areas (ACPT9). } \\
\text { - There will be a willingness to share knowledge and information with neighbors and other people living in the community in the event of implementation of the co- } \\
\text { production project of biomass energy from agricultural wastes and community wastes in nearby community and residential areas (ACPT10). }\end{array}$ \\
\hline
\end{tabular}

Fig. 2: Questions of social acceptance on CO-RDF Project issue 
Generally speaking, consideration of the $\mathrm{R}$ value relies on the following criteria for interpreting the findings: 0.90 to 1.00 and -0.90 to- 1.00 as a highest correlation, 0.70 to 0.89 and -0.70 to- 0.89 as a high correlation, 0.50 to 0.69 and -0.50 to- 0.69 as a moderate correlation, 0.30 to 0.49 and -0.30 to -0.49 as a low correlation, 0.00 to 0.29 and 0.00 to- 0.29 as a lowest correlation.

\begin{tabular}{|c|c|}
\hline Issue & Questions \\
\hline $\begin{array}{l}\text { Awareness of the environmental } \\
\text { and energy crises (AW_ENVI) }\end{array}$ & $\begin{array}{l}\text { - Use of renewable energy and clean energy translates into reduced dependency on fossil fuel, which needs to be wastefully imported from abroad and causes } \\
\text { environmental impacts (EN1). } \\
\text { - Use of renewable energy and clean energy reduces the effects of global warming and climate change caused by the use of fossil fuels (EN2). } \\
\text { - At present, pollution from wastes affects many areas nationwide, and the public holds it an important issue for cooperation to occur as a solution to the problem such as } \\
\text { by separating before discarding to allow utilization (EN3). } \\
\text { - At the present, waste is converted into alternative energy fuel, which should support environmental-friendliness and alleviate problems associated with waste management. } \\
\text { - Thailand has biomass power plants producing electricity derived from biomass fuels such as rice husks, woodchips, etc. spread across many areas in every region. } \\
\text { Consequently, environmental impacts caused by the use of fossil fuels can be reduced (EN5). }\end{array}$ \\
\hline $\begin{array}{l}\text { Awareness of social and community } \\
\text { development (AW_SOC) }\end{array}$ & $\begin{array}{l}\text { - Utilization of agricultural wastes instills conscience in regards to resources for people living in communities ( } \mathrm{SOCl} \text { ). } \\
\text { - Collecting agricultural wastes creates supplementary jobs for farmers ( } \mathrm{SOC} 2) \text {. } \\
\text { - Utilization of agricultural wastes is a start in regards to using discarded materials in communities (SOC3). } \\
\text { - Utilization of agricultural wastes lead to the forming of groups and improved relationships among people living in communities (SOC4). } \\
\text { - Utilization of agricultural wastes promote the image of farmers by adding value to agricultural wastes and can be expanded to achieve other developments (SOC5). }\end{array}$ \\
\hline $\begin{array}{l}\text { Awareness on economic } \\
\text { development (AW_ECON), }\end{array}$ & $\begin{array}{l}\text { - Utilization of agricultural wastes in alternative energy production increases income for you and other people living in your community (ECON1). } \\
\text { - Utilization of agricultural wastes in alternative energy production reduces energy expenses for you and other people living in your community (ECON2). } \\
\text { - Utilization of agricultural wastes in alternative energy production can create sustained industry in addition to jobs from biomass fuel production (ECON3). } \\
\text { - Utilization of agricultural wastes in alternative energy production can lead to the forming of community enterprises resulting from biomass fuel production, while further } \\
\text { leading to self-reliance on energy (ECON4). } \\
\text { - Utilization of agricultural wastes in alternative energy production can sustain family economy when prices for agricultural products are low (ECON5). }\end{array}$ \\
\hline $\begin{array}{l}\text { Awareness on opportunity and } \\
\text { participation } \\
\text { (OPP_PAR) }\end{array}$ & $\begin{array}{l}\text { - You think that leftover materials from plantations can be used as raw materials in alternative energy production in the future. (OPPI) } \\
\text { - If leftover materials from plantations are utilized and processed into other products beyond those that are currently available, the market value of these materials will } \\
\text { increase. (OPP2) } \\
\text { - If in the future the use of leftover materials from plantations in alternative energy production is promoted, revenue will be generated for farmers and you, too. (OPP3) } \\
\text { - You will be able to generate income for yourself if the use of alternative energy from biomass is promoted in the future. (OPP4) } \\
\text { - This is your first step toward making use of biomass and paying attention to the environment and alternative energy and will lead to additional studies for information. } \\
\text { - This is your first step toward making use of biomass and paying attention to the environment and alternative energy and will lead to additional studies for information. } \\
\text { (OP5) }\end{array}$ \\
\hline
\end{tabular}

Fig. 3: Questions of attitude on awareness issue 


\begin{tabular}{|c|c|}
\hline Issue & uestions \\
\hline $\begin{array}{l}\text { Concern on the environment } \\
\text { (CON_ENVI) }\end{array}$ & $\begin{array}{l}\text { - Resistance to power plants or biomass power plants that generate electricity from biomass fuels such as rice husks, woodchips, etc. in many areas gives you concern } \\
\text { about the potential environmental impacts that might occur as a result of the project (COEN1). } \\
\text { - Utilization of community wastes in the production of fuel bars for use in the energy industry raises concerns about environmental impacts resulting from production } \\
\text { processes (COEN2). } \\
\text { - Utilization of agricultural wastes in the production of fuel bars for use in the energy industry raises concerns about environmental impacts resulting from production } \\
\text { processes (COEN3). } \\
\text { - Co-production of community wastes and agricultural wastes in the production of fuel bars for use in the energy industry raises concerns about environmental impacts } \\
\text { resulting from production processes (COEN4). } \\
\text { - Utilization of community wastes and agricultural wastes in the production of fuel bars for use in the energy industry causes environmental impacts (COEN5). }\end{array}$ \\
\hline Concern on health (CON_HEAL) & $\begin{array}{l}\text { - Resistance to power plants or biomass power plants that generate electricity from biomass fuels such as rice husks, woodchips, etc. in many areas raises concern about } \\
\text { potential impacts to the health of individuals and communities as a result of this project (COHE1). } \\
\text { - Utilization of community wastes as raw materials in the production of fuel bars for use in the energy industry raises concerns about individual and community health as } \\
\text { a result of this project (COHE2). } \\
\text { - Utilization of agricultural wastes as raw materials in the production of fuel bars for use in the energy industry raises concerns about individual and community health as } \\
\text { a result of this project (COHE3). } \\
\text { - Co-production of community and agricultural wastes in the production of fuel bars for use in the energy industry raises concerns about individual and community health } \\
\text { resulting from production processes (COHE4). } \\
\text { - Co-production of community wastes and agricultural wastes in the production of fuel bars for use in the energy industry will greatly affect individual and community } \\
\text { health (COHE5). }\end{array}$ \\
\hline
\end{tabular}

Fig. 4: Questions of attitude for project concern issue

\begin{tabular}{|l|l|}
\hline Issue & Questions \\
\hline $\begin{array}{l}\text { Direct incentive for gathering } \\
\text { (INCENT) }\end{array}$ & $\begin{array}{l}\text { - Cost effectiveness and profit influence your decision to gather materials. (INC1) } \\
\text { - Incentives in the categories of prizes, discounts, special privileges, etc. Influence your decision to gather materials. (INC1) } \\
\text { - You are willing to gather any type of material as long as you consider doing so to be economically viable and investment-worthy. (INC3) }\end{array}$ \\
\hline $\begin{array}{l}\text { Indirect incentive for gathering } \\
\text { INDIR_INCENT) }\end{array}$ & $\begin{array}{l}\text { - Non-monetary incentives such as social benefits, environmental benefits, etc. Influence your decision to gather materials. (IND1) } \\
\text { - You are willing to gather any type of materials if you deem that doing so will create activities that benefit the community and society, even if they are not } \\
\text { cost effective. (IND2) } \\
\text { - You are willing to gather any type of materials if you deem that doing so will create environmentally-friendly activities, even if they are not cost effective. } \\
\text { (IND3) }\end{array}$ \\
\hline $\begin{array}{l}\text { Obstacles to gathering } \\
\text { (OBSTACLE) }\end{array}$ & $\begin{array}{l}\text { - Labor is a major obstacle to your gathering of materials. (OB1) } \\
\text { - Your free time is a major obstacle to your gathering of materials. } \\
- \text { Terrain inconveniences are major obstacle to your gathering of materials (OB3) } \\
\text { - Storage facilities are major obstacle to your gathering of materials. (OB4) } \\
\text { - Uncertainties in the purchase price of materials are a major obstacle to your gathering of materials. (OB5) }\end{array}$ \\
\hline
\end{tabular}

Fig. 4: Questions of incentive and obstacle issue

\section{Result and Discussion}

\subsection{Opinion Survey Findings}

This section covers a report on a public opinion survey on the CO-RDF Project. All of research findings are shown in Fig. 6 and Table 1. The interesting issues of the study that could lead to further development are as follows:

When the group of attitude on awareness was considered, it was found that AW_ENVI had a mean score of 3.46. Although the aforementioned value is high, it is counted as the lowest in the category of the aforementioned issue. Furthermore, when awareness of environmental impacts caused by conversion of waste into energy (EN4) and biomass power plants (EN5) were considered individually, both values were moderately high with mean values of 2.93 and 2.92 , respectively.

When the group of attitudes for project concern, which was composed of two sub issues (CON_ENVI and CON_HEAL) was considered, the study found that the sample group had slightly higher concern about the 
environment under the project's implementation. However, both issues produced moderately high scores at mean values of 3.12 and 3.05, respectively. Upon considering individual questions, the sample group had the highest level of concern on impacts resulting from the project's implementation due to resistance against the construction of additional power plants and biomass power plants and the conversion of waste into energy (COEN1-2, COHE1-2). On the other hand, the use of biomass materials as raw materials for energy production produced low-to-least level of concern. However, concern was slightly greater on including community wastes as raw materials in the production of fuel bars but still ranged within a moderate level.

Upon considering group of incentive of obstacles, the study revealed that the sample group perceived direct revenue (INCENT) to the highest degree with mean score at 4.61, while the mean score of INDIR_INCENT was 3.50 and OBSTACLE was moderate with mean score at 3.05.

As for the study's findings on acceptance of the CO-RDF Project (ACCEPT), which consisted of ten issues presented as survey questions, overall, the study found that the majority had a mean score than ranged within a positive direction with acceptance of the project ranging from high to highest. However, some issues produced a moderate mean score, for example, issues concerning guidelines for using biomass materials for other purposes aside from the project (ACP3) and experimentation on gathering of biomass materials and preparation of storage facilities (ACPT5), possibly because the public is waiting for increased clarity about the project. Meanwhile, another important issue is concerned with the possibility that the project on co-production of biomass energy from agricultural wastes and municipal wastes might be implemented in a residential area (ACPT8). The aforementioned finding is consistent with the findings on the group of attitudes for project concern, whereby the concern score would slightly increase if the project was implemented with aspects involving community wastes. It is possible that use of community wastes as raw materials along with biomass materials is a factor that prevents acceptance of the project from reaching its highest level.

\subsection{Correlation analysis of factors correlated with project acceptance}

This section covers correlation analysis of factors correlated with acceptance of the CO-RDF Project that will be implemented in the future. Pearson's Product Moment Correlation Coefficient was used. The study's findings are shown in Table 1, the details of which are as follows:

The factors found to be correlated with acceptance of the CO-RDF Project were awareness of the environmental energy crises, awareness of social and community development (AW_SOC) and opportunities/participation (OPP_PAR). All three of the aforementioned factors have a very low level of correlation with project acceptance. Nevertheless, the aforementioned factors continued to directly affect the project's acceptance. To elaborate, access to information and perception of personal benefits by the public and people living in communities would naturally increase the project's acceptance. Meanwhile, the study indicated that concern for the environment (CON_ENVI) and concern on health (CON_HEAL) is also correlated with project acceptance but with an inverse relationship. In other words, reduced concern directly increases project acceptance, whereby concern on health affects acceptance to a greater extent than concern for the environment. Additionally, problems/obstacles in the gathering of biomass materials (OBSTACLE) is another factor reporting inverse correlations with project acceptance.

The factors not correlated with acceptance of the CO-RDF Project consisted of awareness of economic development (AW_ECON), direct incentives in the gathering of biomass materials (INCENT) and indirect incentives in the gathering of biomass materials (INDIR_INCENT). All of these factors are linked with economic incentives. In addition, considerations of the aforementioned opinion levels showed that the public gave importance to and held opinions from high to the highest levels (Fig. 6). However, no correlations were found with project acceptance with statistical significance 

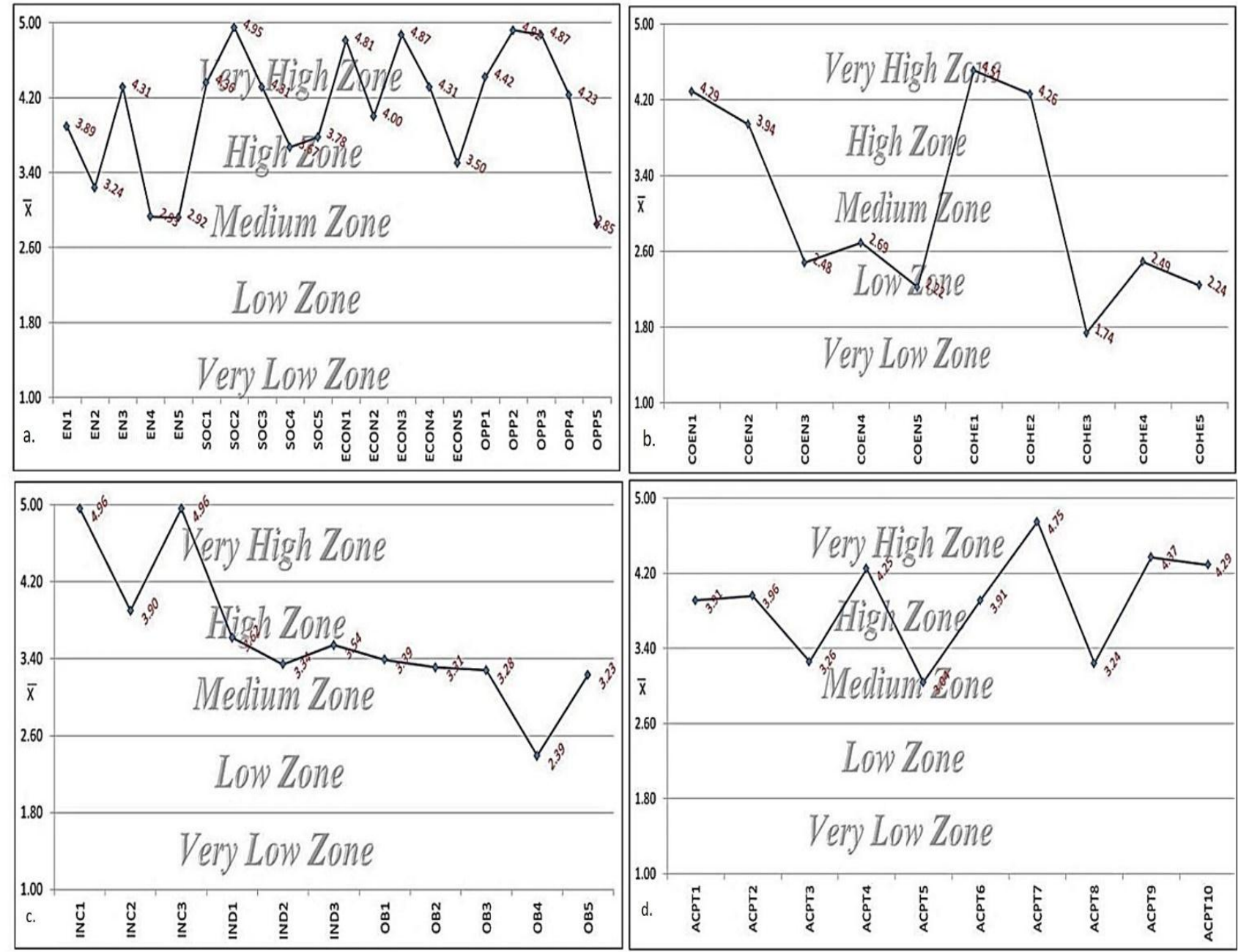

Fig. 6: Result of opinion study (A) Awareness issue (B) concerns issue

(C) incentive and obstacle issue (D) Social accept on Co-RDF Project

Table 1: Results of factor analysis were correlated with project acceptance

\begin{tabular}{|c|c|c|c|c|c|c|c|}
\hline \multirow{2}{*}{ Factor } & \multirow{2}{*}{$\begin{array}{l}\text { No. of } \\
\text { Question }\end{array}$} & \multicolumn{3}{|c|}{ Descriptive Analysis } & \multicolumn{3}{|c|}{ Pearson Correlation Analysis } \\
\hline & & Mean & S.D. & Level & R- Value & Sig. (2-tailed) & Relation \\
\hline AW_ENVI & 5 & 3.46 & 0.48 & High & $0.155^{* *}$ & 0.00 & Lowest \\
\hline AW_SOC & 5 & 4.21 & 0.35 & Highest & $0.135^{* *}$ & 0.01 & Lowest \\
\hline AW_ECON & 5 & 4.30 & 0.34 & Highest & 0.018 & 0.72 & No Sig. \\
\hline OPP_PAR & 5 & 4.26 & 0.29 & Highest & $0.197^{* *}$ & 0.00 & Lowest \\
\hline CON_ENVI & 5 & 3.12 & 0.57 & Moderate & $-0.294^{* *}$ & 0.00 & Lowest \\
\hline CON_HEAL & 5 & 3.05 & 0.57 & Moderate & $-0.365^{* *}$ & 0.00 & Low \\
\hline INCENT & 3 & 4.61 & 0.21 & Highest & 0.013 & 0.80 & No Sig. \\
\hline INDIR_INCENT & 3 & 3.50 & 0.77 & High & 0.015 & 0.76 & No Sig. \\
\hline OBSTAC & 5 & 3.05 & 1.01 & Moderate & $-0.159^{* *}$ & 0.00 & Lowest \\
\hline ACCEPT & 10 & 3.90 & 0.27 & High & 1 & - & - \\
\hline
\end{tabular}

\section{Conclusion}

The present study was a survey research aimed at conducting a public opinion survey on the CO-RDF Project. The findings show opinions regarding acceptance of the project and factors correlated with acceptance. 
The data obtained from the study provide important preliminary information for further development of the project in the future. In conclusion, it can be said that economic factors had no influence over the decision to accept the project's future implementation, whereas access to information to raise awareness and perception about the energy and environmental crises, community benefits, opportunities and community participation in the project in addition to key efforts at reducing concerns about the project possibly in the form of news information and the image presented by various aspects of this type of project are the main factors potentially leading to increased acceptance that facilitates participate in the project's implementation in the future.

\section{Acknowledgements}

We would to thank Energy Conservation Promotion Fund of Thailand (ENCON) for providing the fund for this research. Also with, Phetchaburi Rajabhat University for supporting in conference.

\section{Reference}

[1] Department of alternative Energy Development and Efficiency. 2014, Alternative Energy Development Plan: AEDP2015 (In Thai), Retrieved April 16, 2018, from http://www.eppo.go.th/index.php/th/plan-policy/tieb/aedp

[2] Office of Agricultural Economics. 2016, Agriculture Statistic of Thailand 2015, Nation Office of Buddhism Press, pp. 64-66. (In Thai)

[3] Kttinun Boonrod and Pichet Ninduangdee. 2018, An Opportunity on New Biomass Materials Application for Renewable Energy in Thailand: Perspective of Pineapple Farmers, Proceedings of The 8th International Conference on Languages, Education,Humanities and Social Sciences, 27-29 March 2018, London, UK, pp.71-76 .

[4] Kittinun Boonrod, Pichet Ninduangdee and Awassada Phongphiphat. 2018, Assessment of Energy Potential of Pineapple Residues in Western Thailand, KMUTT Research and Development Journal, Vol. 41(1), pp.47-61 (in Thai)

[5] Pollution Control Department. 2017, Thailand state of pollution report 2016. Hua Yai Co., Ltd., pp. 68-76.

[6] Pollution Control Department. 2014, Road Map on Waste and Hazardous.Waste Management (In Thai), Retrieved April 16, 2018, from http://infofile.pcd.go.th/waste/Roadmapbook.pdf?CFID

[7] Kittinun Boonrod and Awassada Phongphiphat. 2017, The solid fuel development from pineapple and coconut residue and its co-production with municipal solid waste project (Final Report), ENCON Fund. (In Thai) 192 p.

[8] Ch. Achillas, Ch. Vlachokostas, N. Moussiopoulos, G. Banias, G.Kafetzopoulos and A. Karagiannidis. 2011, Social acceptance for the development of a waste-to-energy plant in an urban area. Resources, Conservation and Recycling, 55, 857-863.

https://doi.org/10.1016/j.resconrec.2011.04.012

[9] Cochran, W.G., 1963, Sampling Techniques, $2^{\text {nd }}$ ed. New York: John Wiley and Sons, Inc. 